\title{
A ecologia flusseriana da Comunicação: ideias e conceitos chave*
}

\author{
Marlson Assis de Araújo***
}

\begin{abstract}
Resumo
Vilém Flusser e sua ecologia da Comunicação ainda continuam desconhecidos. O filósofo ensaísta, judeu theco, naturalizado brasileiro, veio para o Brasil em 1940, fugindo do nazismo. No Brasil foram 32 anos de enfrentamentos e engajamentos. Sua comunicologia é profundamente marcada pela experiência brasileira. Destaco sete idéias-chave do seu pensamento comunicacional: A religiosidade como metáfora do senso de realidade; $\mathrm{O}$ consumo e a nulodimensão; A Escalada da Abstração; As três grandes catástrofes; $\mathrm{O}$ conceito de Funcionário; $\mathrm{O}$ produto dos meios de Comunicação - indivíduos hipnógenos; O conceito de Sujeito. A comunicologia flusseriana é: nômade, mestiça, multicultural e antropofágica. Urge resgatarmos seu pensamento instigador e crítico nas análises da sociedade midiática.

Palavras chave: Vilém Flusser. Ecologia da Comunicação. Escalada da Abstração. Funcionário. Sujeito.
\end{abstract}

\section{Flusser ecology of Communication: key concepts and ideas Abstract}

Vilém Flusser and his ecology of communication still remain unknown. The Brazilian-natural Jewish Czech philosopher and essayist went to Brazil in 1940 to flee from Nazism. In Brazil he spent 32 years of confrontation and engagement.

\footnotetext{
* Este artigo é fruto das aulas do prof. Dr. Norval Baitello Junior, do Programa de Pós-graduação em Comunicação e Semiótica da PUC-SP, nas quais participei enquanto doutorando no Programa, assim como também das minhas leituras e incursões na bibliografia citada, além das anotações feitas em sala de aula. Foi a forma que encontrei para consolidar e organizar meu aprendizado. Ao compartilhar esse artigo com a comunidade científica, agradeço muito ao prof. Norval. Qualquer engano ou heresia aqui dita é de minha inteira responsabilidade.

** Doutor em Comunicação e Semiótica pela PUC-SP, teólogo com convalidação pela Pontifícia Faculdade de Teologia Nossa Senhora da Assunção- SP, pesquisador do Centro Interdisciplinar de Semiótica da Cultura e da Mídia (CISC) na área de Mídia e Religião, Pontifícia Universidade Católica de São Paulo-PUC - São Paulo-SP, Brasil.E-mail:marlson@uol.com.br
}

Intercom - RBCC 
His communicology is profoundly marked by his experience in Brazil. We will point out seven key ideas of his communicational thought: religiousness as a metaphor for sense of reality; consumption and nulodimensão ('null dimension'); the Escalade of Abstraction; the three great catastrophes; the concept of Employee; the product of media - hypnogenous individuals; the concept of Subject. Flusserian communicology is: nomad, mixed, multicultural, and anthropophagic. It is urgent that his instigating and critical thought be revisited in the analysis of mediatic society.

Keywords: Vilém Flusser. Ecology of Communication. Escalation of abstraction. Employee. Subject.

\section{La ecología de Flusseriana de la Comunicación: ideas y conceptos fundamentales \\ Resumen}

Vilém Flusser y su ecología de la comunicación todavía continúan desconocidos. El filósofo ensayista, judío checo, naturalizado brasilero, vino para Brasil en 1940, huyendo del nazismo. En Brasil fueron 32 años de enfrentamientos y participación activa. Su comunicología es profundamente marcada por la experiencia brasilera. Destaco siete ideas-clave de su pensamiento comunicacional: La religiosidad como metáfora del censo de realidad; El consumo y la nulo-dimensión; La Escalada de la Abstracción; Las tres grandes catástrofes; El concepto de Funcionario; El producto de los medios de comunicación - individuos hipnóticos; El concepto de Sujeto. La comunicología Flusseriana es: nómade, mestiza, multicultural y antropofágica. Nos urge rescatar su pensamiento instigador y crítico en los análisis de la sociedad mediática.

Palabras clave: Vilém Flusser. Ecología de la Comunicación. Escalada de la Abstracción. Funcionario. Sujeto.

\section{Introdução: Vilém Flusser e a ecología da Comunicação}

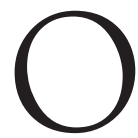

filósofo judeu Vilém Flusser nasceu em 1920 em Praga na antiga Tchecoeslováquia. Veio para o Brasil em 1920, como fugitivo, juntamente com sua namorada Edith Barth, devido à invasão nazista. Casou-se no Rio de Janeiro e depois foi trabalhar em São Paulo, na pequena indústria do sogro até, mais ou menos, 1960. Em seguida se dedicou à filosofia e passou a dar aulas na FAAP, no ITA e na USP. Escreveu para os dois grandes jornais do país, O Estado de São Paulo e A Folha de São Paulo. Publicou mais 
de 30 livros, primeiro em português e depois em várias línguas. Em 1973, foi para Rabion, na França, e passou a publicar na Alemanha, ocasião em que é reconhecido como filósofo dos novos "media". Morreu num acidente de carro em 1991, em Praga, após proferir conferência no Instituto Goethe. O livro Für eine Philosophie der Fotografie, traduzido em mais de 14 países e em português como A filosofia da caixa preta é a sua obra mais famosa. Flusser é considerado um "profeta" da era pós-industrial, das imagens técnicas.

Em artigo aceito pelo XXXIV Congresso Brasileiro de Ciências da Comunicação (de 02 a 06 de setembro de 2011 na UNICAP, Recife, PE), no Grupo de Pesquisa Teorias da Comunicação, apresentamos Uma introdução à Vilém Flusser: um filósofo e comunicólogo brasileiro pouco conhecido (ARAÚJO, 2011), no qual abordamos de forma mais profunda e sistemática a história, trajetória, perfil intelectual e engajamentos deste grande filósofo na cultura brasileira, seu retorno para a Europa após 32 anos de Brasil, até sua morte trágica num acidente de carro quando ia a um oculista na Alemanha, num momento de sua maior projeção internacional como filósofo dos novos media.

Em continuidade, nesse artigo, enumero sete conceitos e ideias chave, fundamentais, para entendermos o pensamento comunicacional de Vilém Flusser, a sua filosofia da mídia, ou, como chamo no título deste, sua ecologia da Comunicação.

Todo pensamento comunicacional tem sua dimensão ecológica. O conceito de ecologia hoje está presente em uma pluralidade de áreas interdisciplinares e cada vez mais apropriado para usos metafóricos. Ultimamente, também, os estudos de Comunicação recorrem à metáfora da ecologia:

Que a Comunicação também faça uso da metáfora ecológica não deve causar espanto. A história da humanidade confunde-se com a história do aparecimento de novas mídias comunicacionais. Começando com a invenção das escritas e do alfabeto, continuou com a prensa manual e, depois mecânica, com a fotografia, o telégrafo, o jornal, o telefone, o cinema, o rádio, a TV etc. A constituição progressiva de uma ecologia midiática salta à vista. Tanto é assim que, com crescente frequência, o campo da Comunicação está fazendo uso da palavra "ecologia" e da descrição dos seus processos para autocaracterizar-se (SANTAELLA, 2010, p.15).

Intercom - RBCC 
Por isso se pode também falar de uma ecologia da Comunicação ou de uma ecologia midiática. O pensador espanhol Vicente Romano $(1993 ; 2004)$ incentiva-nos a pensarmos a Comunicação numa perspectiva ecológica, ressaltando as características qualitativas da Comunicação humana que afetem significativamente a nossa qualidade de vida. Ele analisa as consequências sociais do desenvolvimento tecnológico, destacando os impactos destas transformações em curso na sociedade sobre a Comunicação primária, aquela que se processa a partir dos sentidos humanos. Assim, a proposta de uma ecologia da Comunicação e da cultura ganha espaços nas pesquisas contemporâneas das ciências da Comunicação, chamando a atenção para os desdobramentos e as consequências dos processos midiáticos e culturais em curso com impactos nos ambientes da sociabilidade e dos imaginários. Uma ecologia comunicacional estuda a ecologia dos sentidos, tão descartados nos ambientes tecnológicos e possibilita leituras críticas dos cenários possíveis a partir dos seus contextos midiáticos.

Vilém Flusser nos oferece em suas obras uma ecologia comunicacional, mesmo que, partindo na maioria das vezes, das patologias criadas pelas imagens técnicas, que transformam seres humanos e sociedades em aparatos, em funcionários, para nos indicar e propor um humanismo tão ausente dos processos midiáticos contemporâneos, e que urge resgatarmos, em busca da nossa tão sonhada liberdade, a de recolocarmos o ser humano no centro de tudo, inclusive das mídias e das políticas comunicacionais. E que nesse cenário possível, o mesmo se consolide como sujeito do processo.

Sem esgotar todas as suas ideias e conceitos chave, nesse artigo abordo os seguintes insights (sacadas geniais) para a constituição de uma ecologia da Comunicação flusseriana: a religiosidade como metáfora do senso de realidade; a escalada da abstração; o consumo e a nulodimensão; as três grandes catástrofes; o conceito de funcionário em Flusser; os meios de Comunicação fabricam indivíduos hipnógenos; o conceito de sujeito em Flusser.

\section{A religiosidade como metáfora do senso de realidade}

Se existe um filósofo que atuou no Brasil e que tenha repercussão internacional, este filósofo é Vilém Flusser. Um leitor atento 
perceberá que Flusser em seus escritos, utiliza muitos termos religiosos, do mundo da religião, sem ser religioso. Ou se quisermos, podemos considerá-lo um religioso às avessas, ao seu modo, sempre implodindo com seu pensamento tudo o que se manifeste como verdade dogmática, imutável. Flusser não era religioso no sentido do termo, embora tenha lido muito autores místicos. Sua religião era o pensamento filosófico complexo, era a dúvida. Ele era um judeu sem Deus, um religioso ao seu modo, a exemplo de Freud.

Flusser se inaugura como autor falando sobre o diabo em um país predominantemente católico, com o livro História do Diabo, o primeiro que ele escreveu, antes de Lingua e Realidade (1963). O livro foi escrito em alemão entre os anos 1956 e 1957 mas Flusser não conseguiu publicá-lo pelas editoras alemãs. Traduziu-o depois para o português e, finalmente, conseguiu publicá-lo pela editora Martins Fontes, em 1965. O livro faz uma leitura da sociedade industrial e da sociedade de consumo a partir dos sete pecados capitais: Luxuria, Ira, Gula, Inveja, Preguiça, Tristeza do coração e finalmente Avareza. Um livro muito bom para ler, prazeroso, repleto de ironias à sociedade industrial, à sociedade de consumo. No capítulo sobre a gula está o grande diagnóstico da sociedade contemporânea e da nossa civilização. A gula é muito diferente da fome. A fome visa a suprir as necessidades fundamentais. A gula visa suprir as necessidades supérfluas. Quem é pobre é acometido da fome; quem é rico é acometido da gula. Segundo os budistas a fome não se mata comendo, pois comendo se gera mais fome. Não se pode alimentar o vazio. Ao comer se enche o estomago que depois será esvaziado e enchido novamente.

O que são os instrumentos e máquinas que criamos? Para Flusser, são os excrementos da sociedade. A História do diabo é um livro demolidor. A gula nós dá a perfeita dimensão da um aparato teórico criado por Flusser, denominado de a "escalada da abstração" que abordaremos mais adiante.

O livro Da religiosidade foi publicado primeiramente pela Imprensa Oficial, para a Comissão Estadual de Cultura de São Paulo no ano de 1967. Em uma nova edição, de 2002, pela Editora Escrituras, foi acrescentado ao título Da religiosidade o subtítulo A literatura e o senso de realidade. 
Chamarei de religiosidade nossa capacidade para captar a dimensão sacra do mundo. Embora ela não seja uma capacidade que é comum a todos os homens, é, não obstante, uma capacidade tipicamente humana (FLUSSER, 2002, p.13).

Nos ensaios reunidos no livro, o termo religião volta a aparecer em suas variações e articulações: religiosidade, sacro, fé, transcendência. Flusser considera a literatura como o lugar onde se articula o senso de realidade e explica que "senso de realidade" é sinônimo de religiosidade. A realidade por ele analisada é marcada pela sensação do irreal e pela procura de um novo senso de realidade, portanto, pela procura de uma nova religiosidade (Idem).

Lingua e realidade é considerada a sua obra prima, livro publicado em português em 1963 pela editora Herder. Nessa obra, Flusser esboça a sua filosofia da língua, consciente que essa filosofia é nebulosa e revelando que a língua é o seu compromisso e a sua forma de religiosidade e, também, a forma por meio da qual ele se perde. Para Flusser, a língua é, forma, cria e propaga realidade.

Em Bodenlos, falando sobre atestado da falta de fundamento, o filósofo introduz o leitor no clima desse livro: um clima de religiosidade. Diz ele que:

Nele surgiram todas as religiões, porque são métodos de proporcionar fundamento. Mas é também clima no qual todas as religiões periclitam. Porque nele os fundamentos proporcionados pelas religiões são corroídos pelo ácido do absurdo. Todos os nossos problemas são, em última análise, religiosos. Se nos encontramos sem fundamento, buscamos solução religiosa sem poder encontrá-la. E se sentimos fundamento debaixo dos pés (graças a uma religião ou a um substituto qualquer de religião, ou simplesmente graças à força encobridora do cotidiano), perdemos o verdadeiro clima de religiosidade (mas, possivelmente, tal formulação é, ela própria, resultado da falta de fundamento) (FLUSSER, 2007, p. 19-20).

Assim, para Flusser todos os problemas "essenciais" são religiosos (Idem, p.50). Até mesmo os diálogos que ele promovia com "sua gente" eram feitos em "clima religioso". É o que ele afirma em Bodenlos, referindo-se aos seus diálogos com Milton Vargas, engenheiro e professor de filosofia, diz que Vargas é seu mentor por abrir-lhe múltiplas facetas da realidade brasileira. Seus diálogos 
significavam complementação mútua e profícua e reveladora da realidade (FLUSSER, 2007, p.101). Sobre os seus diálogos refere-se, portanto, a um clima religioso:

Por isso o diálogo se dava (até em momentos aparentemente levianos) em clima religioso. E foi em tal clima que a complementaridade dos dois se revelava extremamente fecunda. Um aprendeu não apenas a tolerar a vocação do outro, mas a reconhecer nela o seu outro lado. $\mathrm{O}$ aspecto mais radical do diálogo era este: a existência mesma de um problematizava a existência do outro. Negavam-se mutuamente. E é isto a verdadeira dialética religiosa (aquilo que o Talmud e o Evangelho chamam "o amor do outro"). Um não era possível por causa do outro, e, portanto, um não era possível sem o outro. E tal dialética se resolve apenas no Totalmente Outro (FLUSSER, 2007, p. 105-106).

Assim, percebemos no pensamento flusseriano uma forte articulação entre o Lebenswelt (mundo da vida) Husserliano e a religião. Sendo religião e mundo da vida constituintes da mesma realidade, é compreensível que Flusser faça uma leitura da cotidianidade a partir de um enfoque religioso, ou melhor, utilizando termos da religiosidade, porque a linguagem religiosa é aquela que melhor aguça a nossa percepção de determinado tempo histórico da realidade. Flusser entendia que a capacidade de perceber a dimensão sacra do mundo, antes de ser uma valoração religiosa, é um potencial profundamente humano.

\section{A escalada da abstração}

O homem, como outros animais, precisa para sobreviver, do outro, desde que nasce até quando morre. Esta sociabilidade não funciona de jeito nenhum se não houver a Comunicação. A Comunicação se dá lebenswelt - no mundo da vida, com o que nós temos de nosso, impropriável pelo outro, que é o nosso corpo, nosso gesto, nossa voz. Este mundo da vida num espaço de três dimensões. E se considerarmos a duração e extensão dessas dimensões, um espaço de quatro dimensões. Nossa Comunicação tradicional é tridimensional. Dependemos desse espaço e deste tempo para nos comunicar. Esta Comunicação é presencial e efêmera. O espaço muda, a gente se desloca, o tempo passa e nós ficamos. 
O que fazem os homens e também os animais para fazer perdurar o efeito da Comunicação, uma vez que a Comunicação é um esforço contínuo, interminável? Comunicar, Comunicação dá trabalho. A primeira lição da ecologia flusseriana da Comunicação é esta: para continuar comunicando temos que alimentar a Comunicação. Tudo o que significa a presença, o homem começa a usar para a Comunicação. $O$ animal coloca o cheiro sobre os objetos. O outro animal sente o cheiro e vai adiante, deixa as suas marcas, faz parte do esforço humano.

Aqui surge a imagem; o que é a marca senão a imagem. Nesta passagem é devorada uma das três dimensões. A pegada é bidimensional. A dimensão temporal se dilata. A imagem continua alimentando o processo comunicativo. Diz o pensador das imagens técnicas, que existe uma subtração a partir da abstração:

O propósito de toda abstração é o de tomar distância do concreto para poder agarrá-lo melhor. A mão segura volumes para poder manipulá-los, o olho contempla superfícies para poder imaginar volumes, o dedo concebe para poder imaginar, e a ponta do dedo calcula para poder conceber. Abstrair não é progredir, mas regredir, é um reculer pour mieux sauter (FLUSSER, 2008, p.18).

O ser humano faz um uso intensivo desta descoberta que é a imagem. Há necessidade de simplificar esta imagem. Isto se dá como uma pane adiante na escalada da abstração. Surge o universo escrito que é muito mais econômico que o universo da imagem. Passamos a operar um mundo, uma existência unidimensional, indo desde o pictograma até a imagem, como observamos na tabela:

\begin{tabular}{c|c|c}
\hline Lebens welt & $4 \mathrm{D} / 3 \mathrm{D}$ & Espaço + Tempo \\
\hline Imagem & $2 \mathrm{D}$ & Plano \\
\hline Escrita & $1 \mathrm{D}$ & Linha \\
\hline Imagem Técnica & $\varnothing \mathrm{D}$ & Ponto \\
\hline
\end{tabular}

Explicando esse processo, diz ele que:

As novas imagens não ocupam o mesmo nível ontológico das imagens tradicionais, porque são fenômenos sem paralelo no passado. As imagens tradicionais são superfícies construídas com pontos. De maneira que, ao recorrermos a tais imagens, não estamos retornando da unidimensionalidade para a bidimensionalidade, mas nos precipitando da unidimensionalidade 
para o abismo da zero-dimensionalidade. Não se trata de volta do processo para a cena, mas sim da queda do processo rumo ao vácuo dos quanta. A superficialidade que se pretende elogiar é das superfícies que se condenam sobre semelhante abismo (FLUSSER, 2008, p.15).

Com o surgimento da escrita, surge o pensamento linear, em linha. Isto significa suprimir as divagações, dispersões. O pensamento lógico possibilitou o surgimento da lógica, da ciência, que passou a criar aparelhos, que por sua vez, passam a substituir a escrita. Os aparelhos inventados pela lógica operam com pontos e por isso são unodimensionais. A imagem técnica (computador, televisão, telão) constitui a representação do holograma, a representação tridimensional desse espaço. O holograma é uma imagem técnica. Esta é a parte dorsal do pensamento flusseriano.

O pai, a mãe e a irmã de Flusser foram assassinados nos campos de concentração nazistas. Lidando com a depressão, o filósofo estudou os místicos medievais. Tanto um quanto o outro lidam com o nada. Se Deus está em toda parte, então ele está no vazio e se está no vazio, não existe mais vazio. O Zen budismo diz que meditar é esvaziar a mente.

Flusser é adorado por todos os que lidam com as novas tecnologias. Mas os filósofos ainda não o assimilaram. Ele estudou os místicos, as ciências arcaicas e a alquimia (mutação). Leu de tudo, mas também, sobre a relatividade. Seu pensamento é muito coerente com a reflexão da física quântica.

A palavra escalada é uma forma arcaica de escada. Escada em espanhol é escalera. Tira uma dimensão, desce um grau. Quando chega ao fim, é o vazio, é o nada. Há muitas perdas, Vamos tirando, tirando até não sobrar mais nada até se chegar ao vazio. Agora não dá mais para perder nada. Temos que recuperar as coisas perdidas.

$\mathrm{Na}$ Alemanha, aconteciam os chamados "Seminários do Celeiro", ${ }^{1}$ uma reunião de comunicólogos importantes. Participa-

\footnotetext{
${ }^{1}$ Internationale Kornhaus Seminare (Seminários Internacionais do Celeiro), organizados por Harry Pross no período de 1984 a 1993 na pequena aldeia de Weiler, nos Alpes alemães. Pross reunia anualmente, em um antigo celeiro de 200 anos, durante uma semana inteira, os mais polêmicos intelectuais. Nestes seminários eles pensavam e discutiam diversos temas, entre eles, a Comunicação e a mídia. Entre os participantes estavam: Abraham Moles, Lev Kopelev, Vicente Romano, Carlo Mongardin, o próprio Vilém Flusser, Harry Pross e muitos outros.
} 
vam Harry Pross e Vicente Romano. Flusser adorava provocar todo mundo que se colocava contra seu pensamento. Quando Flusser afirmava que já não existia mais diferenças entre o holograma e a maça, Vicente retrucava: - Flusser, não temos mais problemas! Você fica com o holograma e eu com a maça! Este exemplo é muito lembrado pelo professor paulista Dr. Norval Baitello Junior, do Programa de Pós-Gradução em Comunicação e Semiótica da PUC-SP.

Somos todos estas dimensões, somo imagens, somos escrita, somos Lebenswelt. Somos ponto, somos linha, somos plano, somos espaço (e tempo). Nós somos a soma destas coisas. Com o surgimento da escrita, surge o conceito de história. Com a imagem técnica e a nulodimensionalidade, a história perde sentido e nós estamos no momento da "pós-história".

\section{O consumo e a nulodimensão}

Flusser não falou sobre ecologia, mas faz referência à mesma como ciência arqueológica. As ciências arqueológicas bebem nas camadas profundas daquilo que é considerado um lixo. É lá nestas camadas profundas que está a novidade.

No texto Consumidora (A consumidora consumida, artigo publicado na Revista Comentário, de 1972) sobre a mulher ele se revela como um Flusser pioneiramente feminista e diz coisas de forma sui generis.

A imagem da mulher no mundo ocidental é uma imagem patriarcal. É uma imagem da mulher que consome. A mulher nessa ótica é fabricada para ser consumidora. Ela é a concavidade que gera a convexidade do homem. O homem destrói-se a si mesmo criando esse padrão destrutivo de mulher. $\mathrm{O}$ filósofo se pergunta:

'Qual é o papel da mulher na sociedade de consumo?' 'Consumir o produzido pelo homem'. Bem no fundo isto implica que a mulher seja, do ponto de vista masculino, lata de lixo, embora por vezes glorificada. Em termos católicos, ela é ora cálice do pecado, ora cheia de graça, mas sempre vasilhame. E por ser lata, ela é mero objeto para o homem, embora talvez seja o objeto exclusivo para o homem. A tragédia justamente é que ela é necessariamente também objeto para si própria, já que ela pode ver-se apenas do ponto de vista masculino. Tal autocoisificação da mulher é trágica não apenas para ela, mas também para o homem, que por isso é 
incapaz de encontrar nela seu complemento. O que nela encontra é apenas uma realização parcial de si próprio, realização essa na qual ele próprio é consumido. Porque a mulher, por ser lata de lixo, não consome apenas os produtos do homem, mas, com isto, o próprio homem, pouco a pouco, e, mais ainda, o homem inteiro, de corpo e alma. Ela é o precipício no qual o homem se lança no seu engajamento cego contra o vazio. De maneira que a mulher é consumidora não apenas dos produtos do homem, mas do próprio homem, e o homem vive para ser consumido por ela. Ela é o futuro do homem, contra o qual se dirige, mas também a morte do homem, e será devorado por ela (FLUSSER, 1972, p.42).

Percebe-se nesse pensamento flusseriano uma contundente crítica à cultura patriarcal, que associa a imagem do feminino a um receptáculo ou vasilhame e em seguida à imagem do abismo, do vazio e da morte. A abordagem de Flusser é uma proposta pioneira do feminino, diferente da proposta midiática (que é induzir as mulheres a tomarem as rédeas da sociedade patriarcal e elas mesmas se transformarem em patriarcais, reproduzindo o sistema patriarcal de dominação).

O renascimento da história trabalha o discurso historiográfico; o renascimento da etimologia aborda a história das palavras. Por exemplo, a palavra cifra, dissecada etimologicamente significa zero, vazio. As cifras são recipientes vazios com objetivo de acolher quantidades de alguma coisa. Já a pisicanálise desenvolvida no começo do século 20 e que vai buscar tudo aquilo que a ciência jogou fora. A psicanálise vai reconstruindo os cacos da vida do paciente que foram jogados fora, de modo que o paciente junte esses cacos e comece a curar-se a si mesmo. Assim, o lixo é parte constitutiva da vida da humanidade e não faz sentido descartar, mas reutilizar. As ciências arqueológicas são ciências que reciclam.

O conceito, a ideia sobre ecologia estão ai presentes em Flusser. Sua proposta de ecologia é a busca do abismal. Todo processo de soterramento e de descarte é abismal. Jogar fora é jogar para um espaço no qual não conhecemos, não circulamos. É só imaginarmos os lixões das grandes cidades. Trata-se de uma imagem tátil, olfativa, repugnante. Lixões são abismos perceptivos. Essa imagem é a imagem do excremento (em A História do Diabo), é a produção industrial que devora a natureza e lança no espaço chamado cultura o resultado da natureza devorada. São excrementos 
jogados pela indústria pra o nosso consumo. É o primeiro Flusser no primeiro livro (embora não o primeiro publicado). Também em Lingua e Realidade ele fala de abismos. A proposta de ecologia de Flusser passa por um momento de lixão - enquanto lugar de vida. Que tipo de vida nasce de um lixão? Uma vida de outro tipo, em efígie, em imagem com a renúncia de todos os sentidos do corpo. São os materiais da nulodimensionalidade. É a escalada da abstração, o processo de descascamento dos produtos da materialidade em abstração. Baitello (2010, p.20) diz que:

Ao invés da devoração e da metáfora da gula, entra em cena a abstração, uma retirada progressiva das dimensões do espaço-tempo, um 'descascamento' progressivo e um desvestir ou despir as coisas de sua materialidade, para transformá-las em não coisas. A rigor trata-se de uma variante da devoração de corporeidades para sua crescente transformação em não corporeidades ou acorporeidades.

Para Flusser, abstrair é subtrair. A nulodimensionalidade é o mundo sem dimensão. Perdemos aqui toda corporeidade, toda espacialidade. Esse abissal gera ambientes e que depois precisamos lidar com eles. Convivemos com essa abissalidade em diversas dimensões da nossa vida. Nesse espaço só é possível sobreviver jogando, mas abstratamente.

Estar presente nos lugares passou a ficar muito caro. Todos os sistemas de Comunicação passam a ficar obsoletos e caros. Não jogamos fora o nosso corpo, não jogamos fora a imagem tradicional, mas jogamos fora a escrita. A imagem técnica continua cada vez mais ocupando espaços crescentes. O espaço do corpo e da presença foi sendo acuado. A moda como sistema de Comunicação, a escrita e os sinais que deixamos. O não espaço (imagens técnicas) ocupa grande parte da nossa vida.

Dietmar Kamper (VILÉM FLUSSER ARCHIV, 1999) ao assistir palestra de Flusser sobre a escalada da abstração escreveu um livrinho sobre As abstrações do corpo - O quadrado antropológico de espaço, plano, linha e ponto" (em alemão, Körper-Abstraktionen - Da anthropologische Viereck Von Raum, Fläche, Linie und Punkt). O corpo e a sua crescente perda na Comunicação contemporânea. Quando mais estivermos imersos nas realidades das imagens téc- 
nicas muito menos estaremos presencialmente com nossos corpos. Flusser criou uma autêntica ecologia da Comunicação. A ideia de escalada da abstração começa com a história da devoração. A Comunicação humana devora etapa por etapa e finaliza em imagem técnica. A partir do sistema binário das combinações de nada e ponto: surgem as imagens técnicas.

Se olharmos os meios de Comunicação nos quesitos: qualidade, conteúdo, engajamento, exercício da cidadania, a geração de um eco sistema mental, daremos razão ao Flusser, quando ele nos aponta com estes instrumentais teóricos analíticos, que os aparatos constroem um cenário midiático de hipnogênia dos receptores e da mídia, incluindo os sujeitos e objetos. Assim, constatamos o cenário de um projeto que não está bem. Mas, o que o tornaria bem? Ao identificarmos um problema, já começamos a resolvê-lo. O que fazer? Primeiro, tomar consciência que é preciso fazer alguma coisa. Talvez surja algo que reprograme o que já está programado. Em segundo lugar, fazer algo, mas não isolados, não individualmente, mas coletivamente como movimento cultural. Individualmente podemos recuperar o exercício da vontade, pois não jogamos fora nossos corpos, nossos jornais, nossos ícones. $\mathrm{O}$ corpo ainda está presente e é a instância do exercício da vontade. Flusser era um otimista incorrigível, pois depositava esperança que o aparelho iria se corrigir.

\section{As três grandes catástrofes}

Num dos "Seminários do Celeiro", já mencionados anteriormente, Flusser deu uma palestra sobre "Reflexões nômades". O tema era o nomadismo. Para Flusser, o homem viveu três grandes catástrofes: a hominização, a domesticação e a castrástrofe sem nome.

A Hominização. A primeira grande catástrofe pode ser denominada por hominização, introduzida a partir das ferramentas de pedra. Nela, "o homem desenvolve ferramentas e persegue sua caça, é nômade como a caça e como o vento; ao andar (como o vento) toca e aprende o mundo" (BAITELLO, 2010, p.52). Na hominização acontece a descida do homem das árvores para a savana, com modificações enormes do corpo, do cérebro e do 
aparato comunicacional do homem. Essa transformação gerou grandes transformações cognitivas. Na Savana, para sobreviver, o homem precisava se deslocar, caminhar. Em alemão "fahron" e que significa deslocar-se. Ao deslocar-se ele desenvolve a capacidade de "erfahren", de conhecer. Daí que as palavras peregrinação, perigo, experiência, conhecimento, são mescladas de sentidos próximos. Experimentar, caminhar, viver as coisas caminhando. Para essa modalidade de ser humano, todo o seu aparato cognitivo é adquirido ao caminhar.

A Civilização ou domesticação. A segunda grande catástrofe é a Civilização ou domesticação, que surgiu a partir da vida nas aldeias com sua consequente sedentarização. Aqui o homem

constrói casas, domestica e cria sua caça; começa a possuir coisas e, como possui, torna-se fixo na terra, não mais pode andar para apreender o mundo; cria as imagens tradicionais e a escrita que substituem o mundo e os seus percursos [e somente apreende o mundo com sua mediação] (BAITELLO, 2010, p.52).

Trata-se de estabelecer casa, fixar-se, assentar-se. Assentar-se foi a segunda grande catástrofe. Assentar-se, em alemão "sitzen" possibilitou "besitzen" que significa possuir. O nômade não possuía, pois se possuísse não poderia carregar pesos em suas mudanças constantes. Ao assentar-se o homem passa a possuir. A segunda catástrofe aconteceu há dez mil anos, com o Neolítico. Quando surgiu a escrita, foi para controlar as posses; a escrita surgiu à serviço do sistema contábil.

A Catástrofe sem nome, ainda em curso atual e caracterizada pelo retorno ao nomadismo, pelo fato das casas se tornarem inabitáveis. É assim que prefere denominá-la o professor Norval Baitello (2010 p. 52), em seus escritos e aulas na PUC-SP. Hoje estamos diante da terceira grande catástrofe. Hoje, perfuramos nossas habitações e as intempéries entram pelos buracos e perfurações, por onde entram os furacões da mídia com suas imagens técnicas a partir das tomadas elétricas. Precisamos retomar o nomadismo, pois somos por natureza, nômades. Aprendemos andando, caminhando, e não acumulando e sentados. 
Enquanto o homem gerado pela primeira catástrofe vivia no espaço-tempo do caminhar e de sua caça, uma referência móvel, o da segunda tinha uma referência fixa, sua terra e suas poses. O homem da terceira catástrofe retorna ao vento, a natureza fluida da informação e dos valores simbólicos (BAITELLO, 2010, p.52).

Eu ousaria denominar esta terceira catástrofe de Nômades sem Corpo, pois se trata de um novo tipo de nomadismo, no qual não é mais o corpo que viaja, que se move, navega ou caminha, mas seu espírito, seu vento nômade.

Flusser encerra a conferência dizendo que chegou a hora de pararmos de sentar e retomarmos ao deus do vento, o deus do nômade, do qual nos refugiamos em nossas casas. Não é a toa que a gente navega, que a gente surfa na Web. A Web implica sempre verbos de movimento. $\mathrm{O}$ problema é que nesse ambiente virtual somos nômades sem corpo (2010: p.52-53). Chegamos então à imaterialidade que caracteriza a sociedade midiatizada pelas tecnoimagens.

Flusser era judeu de Praga, de minoria alemã. Veio para o Brasil fugindo do Nazismo. Sua comunicologia é nômade. Como é uma Comunicação nômade? Ela se caracteriza pela mestiçagem, pelo multiculturalismo. A metáfora do nomadismo é bem adequada para a sua teoria da Comunicação. O nomadismo é o deslocamento em busca do outro, do diferente, da alteridade.

Flusser se fabricou aqui no Brasil dentro de uma cultura antropofágica, de uma cultura da devoração, da devoração do habitante nativo. A presença da antropofagia no pensamento flusseriano é muito forte. O nomadismo tem a ver com abstração, é um gesto de abstração, de devoração do outro. Essa incorporação significa uma concepção de Comunicação. Nesse prisma, Comunicação pode ser definida como incorporação do outro e consequentemente, a sua destruição. Quando se incorpora o outro, a pessoa já não é mais a mesma e nem o incorporado. É uma nova realidade criada pelo que foi acrescentado e pelo que foi excluído. Essa comunicologia de Flusser é muito instigante; comunicar implica em mesclar, praticar a mestiçagem. É o oposto da ideia clássica e funcionalista da Comunicação, que é fazer o outro o meu agente.

Intercom - RBCC 


\section{O conceito de 'funcionário' em Flusser}

$\mathrm{Na}$ década de 60, Flusser publicou três livros no Brasil: Língua e Realidade, História do Diabo e o terceiro livro Da Religiosidade, de 1967, que reúne vários ensaios publicados em diversas revistas e jornais, como O Estado de São Paulo.

Em Da Religiosidade, Flusser escreve ensaisticamente sobre a literatura, filosófica ou não, como o lugar no qual se articula o senso de realidade, entendida por ele, como sinônimo de religiosidade. E religiosidade abordada como a capacidade para captar a dimensão sacra do mundo. No capítulo 8, intitulado Do Funcionário, Flusser (2002, p.84) diz que:

(...) um novo tipo de situação que está se tornando sempre mais frequente. Nesse novo tipo o centro é ocupado pelo aparelho e o horizonte é constituído de funcionários que funcionam em função do aparelho. Reluto com designar o funcionário pelo termo 'homem', já que se trata de um novo tipo de ser que está surgindo.

Para Flusser, o "funcionário perfeito" não tem uma visão de fora do processo por estar inteiramente englobado pela situação e incapaz de superá-la. Toda sua movimentação se dá em função do aparelho. O funcionário é aquele que não consegue superar o movimento linear e circular desse mecanismo de dominação fechado sobre si mesmo. O funcionário é considerado perfeito porque o aparelho ganhou plena autonomia. Ele vive uma vida de funcionário, ou seja, gira em círculos ao redor do aparelho, integrado profundamente ao mesmo, por frequentar círculos estreitos e assiduamente a ponto de chegar a ser confundido com o próprio aparelho. Em Filosofia da Caixa-Preta, Flusser (2002, p.24) diz que o funcionário encontra-se no interior do aparelho e que "em toda função dos aparelhos, funcionário e aparelho se confundem". Ele é funcionário por que exerce função: é propriedade e atributo do aparelho. Na ideologia dessa engrenagem, o funcionário torna-se progressivamente a propriedade mais valiosa do aparelho e o seu progresso é entendido como a sua adaptação ao aparelho, por meio da sua especialização, também progressiva. Adaptando-se ao aparelho o funcionário adquire um papel específico no conjunto do processo de funcionamento. 
Flusser (2002, p.24-25) ao abordar o tema do funcionário no fundo faz filosofia sobre a questão da liberdade do homem dentro de um processo dominado por aparelhos. Estes aparelhos que metaforicamente ele denomina de "Caixas-Pretas":

Um sistema assim tão complexo é jamais penetrado totalmente e pode chamar-se caixa-preta (...). A pretidão da caixa é o seu desafio, porque, embora o fotógrafo se perca em sua barriga preta, consegue, curiosamente, dominá-la. O aparelho funciona, efetiva e curiosamente em função da intenção do fotógrafo. Isto porque o fotógrafo domina o input e o output da caixa: sabe com que alimentá-la e como fazer para que ela cuspa fotografias, Domina o parelho, sem, no entanto, saber o que se passa no interior da caixa. Pelo domínio do input e do output, o fotógrafo domina o aparelho, mas pela ignorância dos processos no interior da caixa, é por ele dominado. Tal amálgama de dominações - funcionário dominando aparelho que o domina - caracteriza todo funcionamento de aparelhos.

E a diferença entre o homem e o funcionário é que o homem pode escolher entre alternativas, o funcionário não, pois este se tornou propriedade do aparelho e a propriedade mais valiosa. $\mathrm{O}$ sistema dominado por aparelhos é sedutor por dar uma falsa ilusão de liberdade. No caso do funcionário, este pensa que é livre, que toma decisões, mas na verdade não é isto que verdadeiramente acontece do ponto de vista filosófico. O funcionário "funciona", se movimenta, age, mas todos os seus movimentos apenas comprovam a "vontade" do aparelho e não a vontade do ser humano. Quando Flusser fala em vontade, não se trata da vontade humana, mas da vontade que foi inserida no aparelho. Mas, como é que o funcionário é dominado pelo aparelho? Justamente quando ele realiza a "vontade" automática do projeto, segundo o qual os aparelhos foram projetados. É assim que Flusser apresenta o aparelho e a sua propriedade, o funcionário.

Mas o processo de uma sociedade regida por aparelhos tem brechas e são por elas que o homem pode vir a reconquistar a sua liberdade e a da humanidade, deixando de ser funcionário de aparelhos programados para programar. Uma vez que aparelhos dependem de funcionários e que ainda não existem "funcionários plenamente perfeitos", a quebra da autonomia do aparelho pode ser feita por estas frestas. Por mais autônomos que os aparelhos 
busquem ser, eles ainda contam com o fator humano para dar-lhes impulso e programação. A busca por liberdade se encontra nesta constatação: "os funcionários mais perfeitos da atualidade ainda conservam vestígios do humano" (FLUSSER, 2002, p.88).

O filósofo profetiza que aparelhos autônomos são perfeitamente realizáveis e eles se tornarão realidade pela própria força do progresso. O próprio progresso é visto por ele como o caminho do aparelho em curso, buscando freneticamente a sua autonomia. Diz ele que "a transformação total daquilo que ainda é natureza e sociedade em aparelho, e a transformação total daquilo que ainda é humano em funcionalismo, é uma questão de tempo" (FLUSSER, 2002, p.88).

\section{Os novos meios de Comunicação fabricam indivíduos hipnógenos}

Em Filosofia da caixa-preta, o Flusser retoma este tema da ferramenta, da máquina e do aparelho. Muitos se enganam logo de início achando que o livro trate do tema da fotografia. Mas, não; Flusser parte do aparelho fotográfico aparentemente inócuo e primitivo, como protótipo de todos os aparelhos produtores de imagens técnicas que surgiram depois dele, desde os gigantes como os administrativos, econômicos e políticos até os minúsculos como os chips que estão presentes em todos os lugares.

Flusser lembra que ontologicamente, trata-se de objetos produzidos e trazidos da natureza para o homem, constituindo assim o que denominamos por cultura. Trata-se de um uso metafórico da cultura para a natureza. Grosso modo, existem dois tipos de objetos culturais: Aqueles que são destinados ao consumo que denominamos bens de consumo e os que são bons para produzirem bens de consumo e que denominamos por "instrumentos". É papel das ciências da cultura ou da ecologia da Comunicação escavar para descobrir a intenção que se esconde nos fenômenos, como, por exemplo, nos instrumentos. A máquina fotográfica é metáfora para todos os demais instrumentos ou aparelhos que surgiram e que ainda surgirão. Curiosa e instigante é a definição que Flusser (2002, p.19) dá para o conceito de aparelho: 
Etimologicamente, a palavra latina apparatus deriva dos verbos adparare e praeparare. $\mathrm{O}$ primeiro indica prontidão para algo; o segundo, disponibilidade em prol de algo. O primeiro verbo implica o estar à espreita para saltar à espera de algo. Esse caráter de animal feroz prestes a lançar-se, implícito na raiz do termo, deve ser mantido ao tratar-se de aparelhos.

O homem, ao inventar as máquinas, tornou-se funcionário da máquina. No tempo das ferramentas, elas eram as funcionárias do homem. Com a invenção das máquinas o homem passa a girar em torno delas, ao operá-las. Quando só usava as ferramentas o homem fazia a sua própria vontade. Com o surgimento de aparelhos, estes passam a ser programados e nós executamos apenas algumas possibilidades do programa. $\mathrm{O}$ aparelho incorpora a vontade e não é mais a pessoa que quer e sim o aparelho que passa a dominar a nossa vontade, transformando-nos em seus funcionários. Deus sonhou o homem e ficou descontente, pois a sua criatura ficou imperfeita. O homem criou a máquina e a achou imperfeita. A intuição de Flusser está no tema filosófico da vontade e quando se teoriza a questão da vontade no campo filosófico, constata-se embutida nela a questão do poder. Assim, o quadro abaixo nos ajuda a entender as mudanças ocorridas na sociedade:

\begin{tabular}{|l|l|l|}
\hline IDADE MÉDIA & RENASCIMENTO & CONTEMPORANEIDADE \\
\hline Deus & Homem - Livre arbítrio & $\begin{array}{l}\text { Aparelhos com vontades e seus } \\
\text { funcionários, os homens. }\end{array}$ \\
\hline
\end{tabular}

Hoje, o homem não tem o livre arbítrio. Esta figura do funcionário faz a gente refletir sobre um monte de coisas: família, as relações humanas, a sociedade, a mídia etc. A contemporaneidade, marcada pela centralidade e predominância dos aparelhos tecnológicos nos remete ao conceito de hipnogênia. Hipnogênia é quando as pessoas chegam ao estado hipnótico (de hipnose) e simplesmente elas agem de acordo com a maré que as leva para onde ela quiser levar. Baitello (In: RODRIGUES [Org.], 2008, p.97) assim se refere ao estado hipnótico:

Tornava-se por aceita e tranquila a concepção de que os veículos comunicativos, os chamados 'meios' ('media' ou, ainda, 'mídia'), tendem a substituir (ou ao menos ocultar) seus produtores, conduzindo o telespectador à ilusão

Intercom - RBCC

São Paulo, v.35, n.2, p. 373-396, jul./dez. 2012

391 
de que são autônomos e imperativos (por seu lastro material ou por sua autoridade baseada na presença contínua de seus sinais). Seria como se não houvesse ninguém, ou quase ninguém, por trás de um jornal, de uma transmissão de rádio ou de televisão, a não ser o próprio jornal, a emissora de rádio ou de TV. A hipnogenia transfere ao meio toda a responsabilidade, mas também toda a capacidade de decisão, deixando seus agentes no espaço-tempo de uma quase-hipnose, abrindo mão de sua intencionalidade, de sua história e de seus sonhos, de sua vontade, de sua autodeterminação.

O ser humano abre mão de suas vontades e isenta-se das suas responsabilidades, delegando-as às máquinas, aos aparelhos. O sujeito hipnógeno é assim: despido da capacidade de autodeterminação.

Os novos sistemas de Comunicação criaram, não apenas sujeitos, mas, sobretudo, objetos. E objetos que não têm a responsabilidade de tomar decisões. As decisões estão transferidas para outras instâncias contidas nos processos de produção dos aparelhos tecnológicos.

Costuma-se dizer que é o Ibope que aponta o que o público quer. Mas será mesmo que é assim? Na verdade, não é o público que quer, mas o modelo de negócios que determina como serão as coisas. As cadeias do querer fabricam o público que desejam. Trata-se do que Edgar Morin (2007) denominou de a fabricação do consumidor. Este modelo de mídia produz um receptor infantilizado, emburrecido. As pessoas não tem que escolher nada, pois o sistema mediático já escolheu no lugar delas. É o mesmo macanismo do sistema Totêmico. Se você pertence a determinado Totem, tem que seguir aquele Totem. Acontece uma repressão no processo de midiatização. $O$ funcionário flusseriano é este indivíduo hipnótico de um objeto hipnótico.

Quando o homem não consegue transcender o aparelho, acaba sendo triturado automaticamente e inumanamente pela engrenagem do mesmo. Contemplando o aparelho funcionando, com sua propriedade, o funcionário, nos invade a sensação do absurdo na qual o ser humano se colocou. E surgem as perguntas indomáveis: Que progresso queremos? Que tipo de homem pretendemos ser? Que rumos desejamos para a humanidade? Que valores buscamos? O filósofo aponta o caminho filosófico como saída, pois só ele é 
capaz de colaborar na formulação de valores e apontar rumos para o progresso, salvando o ser humano da sua própria anulação.

\section{Conceito de 'sujeito' em Flusser}

Flusser quando morreu, deixou dois livros inacabados. São respectivamente, Vom Subjekt zum Projekt, (Do sujeito ao projeto) e Menschwerdung, (Hominização), editados e publicados em 1994 pela viúva Edith Flusser e pelo editor Stefan Bollmann. No primeiro, Flusser (1998) apresenta o conceito de sujeito. Uma vez que já não temos mais vontade própria, não somos mais sujeitos de nada. O subjeto - é o que está por debaixo para impulsionar minha ação. Tem a ver com resistência e oposição.

Hoje, não existe mais nem sujeito nem objeto. As nossas decisões já estão programadas. Se elas estão programadas eu não sou sujeito coisíssima nenhuma. Não somos sujeitos e nem objetos. Somos projetos, alvos de uma projeção, de um programa. Programados por um programador já programado para programar por outra instância programada do aparelho. O esquema pode ser representado assim:

\section{APARELHO $\rightarrow$ PROGRAMADOR $\rightarrow$ APARELHO $\rightarrow$ PROGRAMADOR}

Flusser retomará este pensamento complexo em um de seus livros mais recentes, O universo das imagens técnicas, de 1985, que se apresenta como uma espécie de aprimoramento do seu ensaio mais famoso, Filosofia da Caixa preta, de 1983 (edição alemã). Em O universo das imagens técnicas são abordados os temas das imagens técnicas e os parelhos a partir de uma análise fenomenológica:

A partir do método que valoriza o ponto de vista subjetivo, o autor pergunta: o que são as imagens técnicas para nós? Como as percebemos e como nos relacionamos com elas? A resposta flusseriana é que a essência das imagens técnicas está na sua superfície, porque são as superfícies que percebemos e a partir delas criamos nossas vivências das imagens técnicas. As imagens técnicas são superfícies compostas de pontos que emitem seu significado ao emissor para que seja informado conforme esse significado. Mas qual é esse significado que informa nossa sociedade? O significado 
das imagens é o seu programa. O programa parte do aparelho que é, por sua vez, programado pela fábrica; a fábrica é programada pelo aparelho do parque industrial, o parque industrial pelo aparelho socioeconômico e esse pelo aparelho político-cultural. O aparelho político cultural, no caso capitalista, quer se manter vivo e funcionar cada vez melhor. Por isso, ele programa o aparelho socioeconômico para programar as fábricas para produzir mais aparelhos, que vão divertir e distrair os homens. Os homens, satisfeitos com seus brinquedos, deixam-se facilmente programar para exigir novos aparelhos, ainda melhores, e o sistema continua funcionando (BATLICKOVA, 2010, p.146).

A cadeia se dilui tão longe que a gente não tem condições de interferir na programação. Não estamos nunca no lugar onde estamos. Somos sempre a possibilidade de alguma ação qualquer. Somos sempre alguma coisa que pode acontecer como uma promessa. Ao se imaterializar o mundo do subjecto nós nos tornamos projeto e do projeto nos tornamos projétil, uma bala disposta a explodir. O projétil é o exercício do possível, do provável, algo que pode ser projetado. Projeto do projeto da imaterialização.

\section{Conclusão}

A ecologia da Comunicação flusseriana é: nômade, mestiça, multicultural e antropofágica. Suas ideias, conceitos e pensamento comunicacional ainda são poucos estudados e sistematizados nos meios acadêmicos. O filósofo theco judeu naturalizado brasileiro viveu 32 anos no Brasil e a ecologia comunicacional extraída de suas principais obras escritas é profundamente marcada pela experiência brasileira. Urge resgatarmos seu pensamento instigador e crítico nas análises da sociedade midiática e como conteúdos programáticos nas grades de disciplinas no campo das Ciências da Comunicação. Aqui abordamos algumas de suas ideias e conceitos chave, sem a pretensão de esgotá-los, pois muito ainda tem para ser dito sobre Vilém Flusser, um filósofo profundo, militante das causas nas quais acreditava, polêmico, sedutor e instigante. É o desafio ora apresentado aos estudantes e pesquisadores de Comunicação. 


\section{Referências}

ARAÚJO, Marlson Assis de. Uma introdução à Vilém Flusser: um filósofo e comunicólogo brasileiro pouco conhecido. In: XXXIV CONGRESSO BRASILEIRO DE CIÊNCIAS DA COMUNICAÇÃO. Recife, 2 a 6 Set. 2011. Anais. Disponível em http://www.intercom.org.br/papers/nacionais/2011/resumos/R60592-1.pdf Acesso em: 23 ago. 2011.

BAITELLO JUNIOR, Norval. Corpo e imagem: Comunicação, ambientes e vínculos. In: RODRIGUES, David (Org.). Os valores e as atividades corporais. São Paulo: Summus, 2008. p. 95-112.

. A serpente, a maça e o holograma: esboços para uma teoria da mídia. São Paulo: Paulus, 2010.

ROMANO, Vicente. Desarrollo y progreso: por una ecología de la comunicación. Barcelona: Teide, 1993.

Ecologia de la comunicación. Hondarribia: Argitaletxe Hiru, 2004.

BATLICKOVA, Eva. A época brasileira de Vilém Flusser. São Paulo: Annablume, 2010.

BERNARDO, Gustavo; FINGER, Anke; GULDIN, Rainer. Vilém Flusser: uma introdução. São Paulo: Annablume, 2008.

FLUSSER, Vilém. Da religiosidade: a literatura e o senso de realidade. São Paulo: Escrituras Editora, 2002.

. Filosofia da caixa preta: ensaios para uma futura filosofia da fotografia. Rio de Janeiro: Relume Demará, 2002.

. A consumidora consumida (isto é: a mulher vista pela sociedade que a faz consumir e que a consome). Comentário: revista trimestral que comenta o mundo e seus problemas, v. 13, n. 51, 3ํ trim. p. 35-46, Rio de Janeiro, Primor, 1972.

. O universo das imagens técnicas: elogio da superficialidade. São Paulo: Annablume, 2008.

. A história do diabo. São Paulo: Annablume, 2008.

2007.

. Bodenlos: uma autobiografia filosófica. São Paulo: Annablume,

Intercom - RBCC

São Paulo, v.35, n.2, p. 373-396, jul./dez. 2012 


\section{MARLSON ASSIS DE ARAÚJO}

FLUSSER, Vilém. Língua e realidade. São Paulo: Annablume, 2007. . Kommunikologie. Frannkfurt/Main: Fischer, 1997. Fischer, 1998 .

. Vom Subjekt zum Projekt - Menschwerdung. Frankfurt/Main:

KAMPER, Dietmar. Körper-Abstraktionen. Das anthropologische Viereck Von Raum, Fläche, Linie und Punkt. Vilém Flusser Archiv: Colônia, 1999.

MORIN, Edgar. Cultura de massas no século XX: neurose. Rio de Janeiro: Forense Universitária, 2007.

SANTAELLA, Lucia. A ecologia pluralista da Comunicação: conectividade, mobilidade, ubiquidade. São Paulo: Paulus, 2010. 